\title{
Inuksuit en el oeste de Groenlandia: símbolo y huella de la relación ancestral de los inuit con el espacio
}

\author{
Santiago David Domínguez-SolerA \\ Codirector de ARES Arqueología y Patrimonio Cultural C. B. \\ cazadorrecolector@hotmail.com
}

Recibido: 18 de febrero de 2013

Aceptado: 7 de abril de 2013

\section{RESUMEN}

El presente artículo define y explica un tipo de construcciones típicas de la cultura tradicional inuit: los inuksuit. Se describen a continuación los trabajos de prospecciones y entrevistas realizados por el autor en el oeste de Groenlandia al respecto de tales estructuras, para terminar explicando su valor como formas de entender y, por tanto, construir el espacio.

Palabras clave: Inuksuit, Groenlandia, inuit, Arqueología del Paisaje.

\section{Inuksuit in Western Greenland: Symbol and Trace of the Inuit Ancestral Relationship to Space}

\begin{abstract}
The present paper defines and explains this typical kind of buildings of traditional Inuit culture. Then, describes the prospection and interview works conducted by the author in West Greenland about these structures, finally explaining their value as ways to understand and, therefore, to build space.
\end{abstract}

Key words: Inuksuit, Greenland, Inuit, Landscape Archaeology.

Sumario: 1. Introducción: ¿Qué son los inuksuit? 2. Inuksuit del oeste de Groenlandia. 3. Conclusiones. 4. Referencias bibliográficas.

\section{Introducción: ¿Qué son los inuksuit?}

Por su etimología, inuksuk significa en el idioma de los inuit «algo relacionado con el ser humano»: inuk 'ser humano' y suk 'algo relacionado con' (Alonso 2006: 206); el plural es inuksuit (Stefánsson 1922). En Nunavut y en Groenlandia se emplearon antiguamente los términos inussuk e inussuit (Grønnow et al. 1983: 41-45; así puede consultarse en internet). Aquí utilizaremos la terminología actualmente en uso.

Los inuksuit consisten básicamente en amontonamientos de piedras colocadas directamente unas sobre otras (en seco) y son típicos del paisaje cultural de los inuit. Durante milenios han sido, y aún lo son, las construcciones humanas más perceptibles y numerosas en esta parte del Ártico. En un entorno carente de árboles, de tundra radical, son por definición hitos artificiales visibles y llamativos. En cientos y miles de kilómetros de tierra casi virgen y deshabitada significan exactamente eso: «algo relacionado con el ser humano».

El material siempre presente en ellos es la piedra, aunque también se encuentran ciertos tipos con partes de madera y hueso, además de otros materiales modernos en los casos más recientes, tales como barras de metal. Varían sus formas desde meras 
piedras clavadas en el suelo a dos piedras una encima de otra, amontonamientos de media docena de piezas, grandes montones de cientos de ellas, a modo de ventanas, o emulación de figuras antropomorfas, de animales y kayaks.

Etimológicamente, el origen de la palabra -y se quiere que, por extensión, también lo sea el de este tipo de construcciones- se ha determinado antes de la aparición de la cultura Thule, hacia el primer milenio a.C. (Alonso 2006: 206-207). Por supuesto, aquí queremos advertir que, aunque no se llamasen inuksuit, bien pudieron existir antes. Hallendy (1997: 43) sugiere que los inuksuit pueden proceder de la época de la cultura Dorset, hacia el 2000 a. C. Es difícil documentar y datar cuáles son las más antiguas por problemas lógicos de conservación, dada su fragilidad estructural ya que las piedras en equilibrio no se traban entre ellas por ningún medio. Pero a pesar de que no se unen con masa u otras técnicas, un inuksuk se hace para que dure para siempre; textualmente, su constructor lo desea así al terminar: nakalanagu! (Alonso 2006). Estas estructuras pétreas están firmemente arraigadas en el bagaje cultural inuit, siendo protagonistas incluso de mitos sobre la naturaleza y orígenes de los inuksuit (Alonso 2006: 208).

Existen varios tipos de inuksuit, además de otras estructuras confeccionadas en piedra, sobre las que no existe consenso de si son realmente o no tales (Alonso 2006: 211-212). Heyes habla de unos 24 tipos conocidos, asegurando por otro lado que se pueden clasificar en algunos subgrupos menores (Hallendy 1992; Heyes 2002). Los nombres varían según los tipos: niungualiruluit inuksuit son piedras verticales y horizontales, conformando una ventana; tikkuutiit o inuksuit marcan direcciones con rocas altas o palos y sirven para recordar caminos seguros, áreas peligrosas, lugares buenos para pescar o cazar, para hacer agujeros en el hielo; qaujisarialik es el nombre de los inuksuit hechos para indicar también pasos peligrosos; aulaqquat (scarecrow, bogeyman, flag) son un tipo de estructuras destinadas a señalizar cazaderos de caribú, sitios por donde cruzar el agua, al mismo tiempo que sirven como elementos intimidatorios para guiar a los animales a las emboscadas... Los anteriores tipos (Heyes 2002: 137-138) son denominaciones para el caso canadiense ya que, por supuesto, los nombres y usos concretos varían por zonas y según los idiomas. Sin poder extendernos aquí demasiado en la resolución de este conflicto, hemos optado por hablar de inuksuit en el sentido amplio del término, dado que las disquisiciones de si tal o cual caso es realmente un inuksuk o no lo es no existen sólo entre los investigadores, sino que -por lo que se deduce tras consultar bibliografía- los propios informantes inuit tampoco llegan a consensuar sus clasificaciones.

Se conocen las diversas funciones que cumplen los inuksuit gracias a los testimonios actuales de las gentes del Ártico, pues o bien se siguen empleando y construyendo o se saben explicar como parte de las tradiciones del pasado. Además es muy útil la información plasmada en las fuentes etnohistóricas, dado que los inuksuit, por su naturaleza, son y eran llamativos para los exploradores y colonizadores europeos (Graburn 2004: 71). Así, por ejemplo, Therkel Mathiassen, en la «Fifth Thule Expedition» (1921-1924) documentó el uso de inuksuit como señalizadores de rutas entre el Cabo Wilson, Usugarssuk, Iglulik y Repube Bay (Heyes 2002: 137). Indican áreas de paso de caribúes y, en forma de kayak, pueden señalar cazaderos de ballenas y de focas, también pasos peligrosos, caminos por tierra y por mar, la cercanía de un 
poblado o campamento y también indican áreas simbólicas, de importancia religiosa. En otros casos, muertos sus constructores y olvidados por consiguiente su mensaje y razón de ser, sirven para homenajear a los cazadores del pasado como «ruta de los héroes» (Alonso 2006: 210).

Norman Hallendy (1992), quien estudió concentraciones de inuksuit en el sudoeste de la Isla de Baffin, define a los inuksuit como semaliths o mensajes creados en piedra, como algo integrado dentro del lenguaje de los cazadores y también parte indeleble del paisaje ártico. Además de los diversos usos constatados, hay otras funciones, otros mensajes cifrados en los inuksuit que, tal vez, sólo supieran sus constructores. Muchos se hacían y se hacen para recordar el punto donde se ha cazado, donde se ha estado (Graburn 2004: 70), donde se quiere volver por razones varias; un cazador en particular le puede dejar un mensaje personal a otro cazador concreto... Ello da lugar a una aleatoriedad difícil de sistematizar por completo mediante denominaciones y tipologías. Pero, al margen de la diversidad, aquí nos interesa ante todo el que un inuksuk siempre actúa como un marcador espacial. Tal función es común a todos los casos, independientemente del mensaje implícito y/o explícito en cada uno de ellos. Esa funcionalidad diversa supone, lógicamente, que algunos inuksuit funcionen individualmente, por si mismos, y otros dentro de un sistema, colectivamente.

Por otro lado, no sólo han de someterse a análisis los inuksuit por su funcionalidad: la mayoría de informadores e investigadores coinciden en que tienen algo «like a human», no sin razón algunos tipos de inuksuit buscan imitar la forma de seres humanos (Graburn 2004: 70). Heyes (2002) describe los inuksuit como algo que no es meramente funcional, pues también tienen explicaciones religiosas y aparecen en mitos y ritos chamánicos. Pero su entidad más allá de lo meramente físico y/o funcional, reside en el simbolismo más que en la atribución de un espíritu o una fuerza espiritual implícita en los inuksuit. Según explica Heyes, la existencia de una creencia generalizada de que ciertos inuksuit poseyeran fuerzas espirituales no queda del todo clara tras analizar los testimonios orales o las fuentes escritas (Heyes 2002: 139). Aunque no cabe duda de que servían para rememorar eventos especiales y eran indispensables para ayudar a los cazadores en sus viajes, y sirvieron también a los exploradores extranjeros dada su utilidad efectiva en el medio ártico (Heyes 2002: 142). En cualquier caso, los autores poco o nada interesados en aspectos simbólicos (Binford 1988: 137-137), aunque obvien los hechos que van más allá de lo meramente físico, nos permiten comprender la verdadera entidad cultural de estas señales de piedra al describirlas en sus obras.

Eran construidos normalmente por hombres, aunque en tiempos históricos las mujeres hacían, el área de los inuit canadienses, un tipo concreto (iqaluqarniraijuq), que consiste en dos piedras, una roja y otra gris o negra, para indicar, por ejemplo, zonas buenas para pescar (Alonso 2006: 208). Los niños también los construyen jugando a imitación de los adultos (Alonso 2006: 208-209).

Presentes o, más bien dicho, omnipresentes tanto en Alaska, como en Canadá y Groenlandia, es sobre los inuksuit canadienses sobre los que más estudios se han realizado (Alonso 2006; Graburn 2004; Heyes 2002). Aunque Binford los llama «piedras del soldado», los menciona dentro de sus trabajos con los nunamiut de Alaska afirmando que, los amontonamientos de piedra que se encuentra en el Lago Tulugak, 
servían para la caza del caribú señalando sus rutas y para intimidar a los animales dirijiéndolos a un punto donde abatirlos más fácilmente, poniéndolos para ello incluso ropas encima (Binford 1988: 136-137).

Un inuksuk preside la bandera y el escudo de armas de Nunavut (Figura 1), territorio independiente dentro del Estado de Canadá, de mayoría poblacional inuit, constituido a partir del 1 de abril de 1999. Concretamente la bandera consiste en un inuksuk rojo, combinado con la estrella Polar. Por otro lado, el escudo de armas mezcla el anterior motivo con otros símbolos relacionados con la identidad inuit en el presente, tales como un narval y un caribú. Rubricando su papel como símbolo identitario de los inuit hoy, se venden figurillas imitándolos, a modo de souvenir. Graburn (2004) explica que, al igual que ha ocurrido en otras partes de América, los inuit de Nunavut han tomado símbolos del pasado para crear su iconografía identitaria dentro de sus nuevos territorios nacionales. Este autor también indica que los inuksuit también se emplean como logotipos de marcas comerciales del Ártico (Graburn 2004: 75), degeneración del significado original en atención a nuevos condicionantes y su motivación actual. Hay quien habla de los inuksuk como símbolo nacional pan-ártico (Heyes 2002: 134). Pero merece la pena destacar que la esencia original siegue siendo recordada: En la Web oficial de Nunavut (www.gov.nu.ca) se explica que el inuksuk que preside la bandera -diseñada por Andrew Karpik- servía en el pasado «para guiar a la gente y marcar lugares sagrados». También explica Graburn (2004: 77) que algunos inuit critican el diseño elegido para la bandera -de entre las 500 opciones que participaron en el concurso de ideas- por diversas razones que lo alejan de la idea tradicional: porque parece una mujer, porque es completamente rojo, porque sólo tiene una pierna y no dos como los inuksuit que intentan ser humanos, porque parece una cruz cristiana... En cualquier caso, otros muchos defienden el símbolo como la reinterpretación de los inuksuit en atención a la identidad inuit actual: si parece una cruz, ello sirve para simbolizar que los inuit son cristianos en el presente. Graburn (2004) critica aquella corriente de opinión que asegura que elegir elementos como el inuksuk fomenta la alteridad, la identidad nueva a través de estereotipos forjados por el hombre blanco: nadie ha forzado a los inuit a escoger este símbolo o las «kamik» (botas de piel de foca de los trajes tradicionales inuit), los perros o los trineos. Son objetos que se llevan empleando desde el pasado y sirven al recuerdo de éste como legitimadores de la nueva identidad, como mensajes propios del territorio ante el sistema del Mundo Globalizado, como marca identitaria dentro de él.

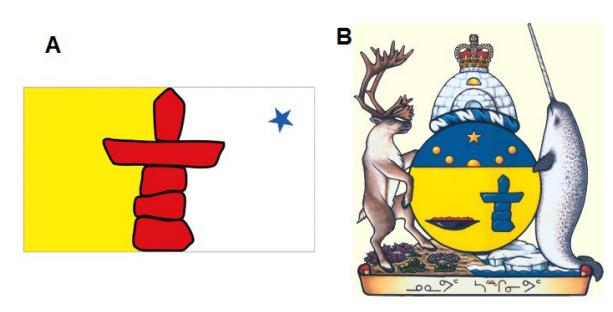

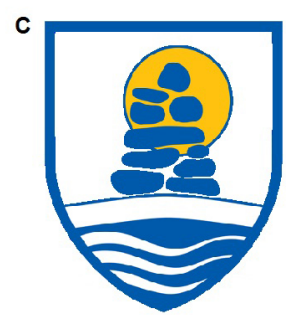

Figura 1: A y B:

Bandera y escudo de Nunavut. C: Escudo de Sermersooq. 
Figura 2: Situación de Nuuk, Kapisillit y Atammik. (Sobre imagen de satélite de Google Maps).

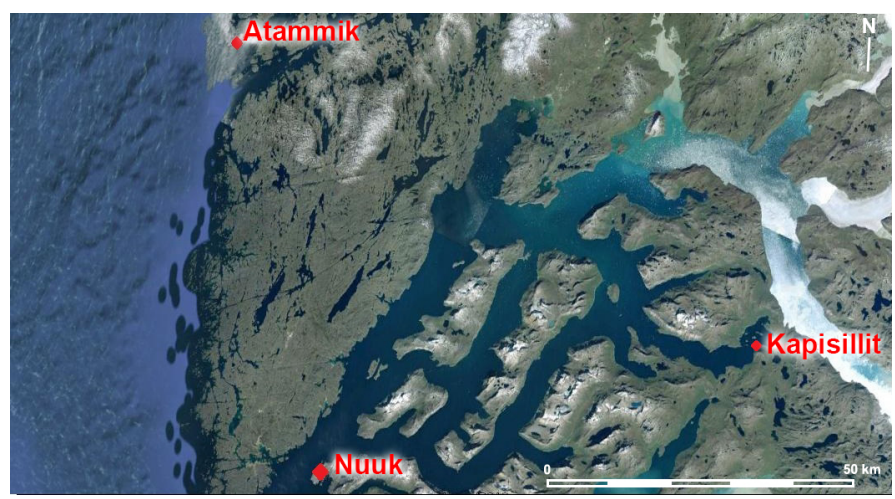

En este artículo todo lo anterior resulta interesante, pero importa ante todo el hecho de que un inuksuk haya sido elegido, nada menos, que como motivo central de una bandera nacional.

Por ser un fenómeno unitario dentro del área cultural inuit, los resultados y las conclusiones emanadas de los casos documentados en Canadá y en Alaska sirven para interpretar los inuksuit del oeste de Groenlandia aquí analizados. Se han estudiado conjuntos o sistemas de inuksuit arqueológicos en Groenlandia, en Asivissuit (Grønnow et al. 1983: 41-45) interpretándose principalmente como un gran sistema para la caza del caribú, para indicar la ruta migratoria y las estrategias a seguir, entre otras funciones que cumplen los amontonamientos individualmente.

\section{Inuksuit del oeste de Groenlandia}

Durante la realización de un viaje en agosto de 2012 para investigar la caza, la pesca y la recolección en el presente y el pasado del caso groenlandés, se realizaron una serie de prospecciones y entrevistas en el oeste de Groenlandia destinadas a obtener información sobre los inuksuit en este importante país de la geografía inuit. Concretamente los datos que vamos a exponer proceden de Nuuk -la capital de Groenlandia-, Kapisillit - una aldea de 75 habitantes a pocos kilómetros al este de tal ciudad-y de Atammik -aldea costera de 200 habitantes al norte de Nuuk y al sur de Maniitsoq(Figura 2).

En Kapisillit, el autor y el cámara Alejandro Pacios, tuvimos constancia de la importante presencia de inuksuit en las inmediaciones del pueblo mientras acompañábamos a sus habitantes a cazar el caribú. Los primeros días, en los que el mal tiempo imposibilitó abatir animales, pudimos además comprobar cómo los primeros inuksuit que veíamos eran perceptibles desde grandes distancias.

Fue sobre todo acompañando al cazador Jakob Josefsen, de 59 años, por un valle al sureste del pueblo (Figura 3), cuando pudimos observar más estructuras (Figura 4), coincidentes en gran medida con la ruta que llevábamos hacia el refugio/campamento de éste. Al preguntarle a Jakob qué eran, éste nos dijo que no sabía qué significaban exactamente, pero que eran señales. Al preguntarle quién las hacía, nos dijo 


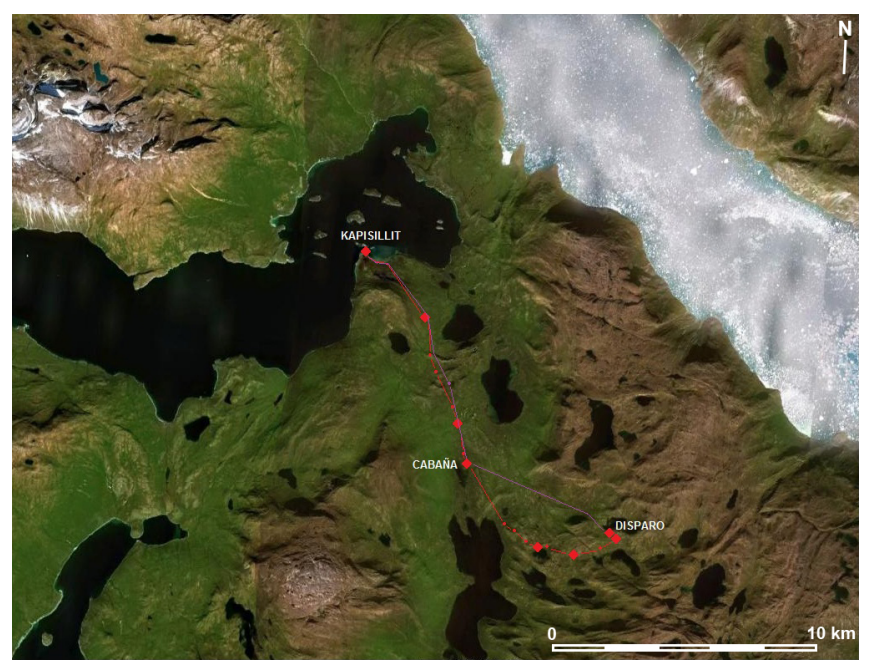

Figura 3: Jornada de caza con Jakob Josefsen, en el área en el que se documentaron varios inuksuit; la línea compuesta indica la trayectoria de ida, la línea simple la trayectoria de retorno y los rombos lugares de descanso. (Sobre imagen de satélite de Google Maps).
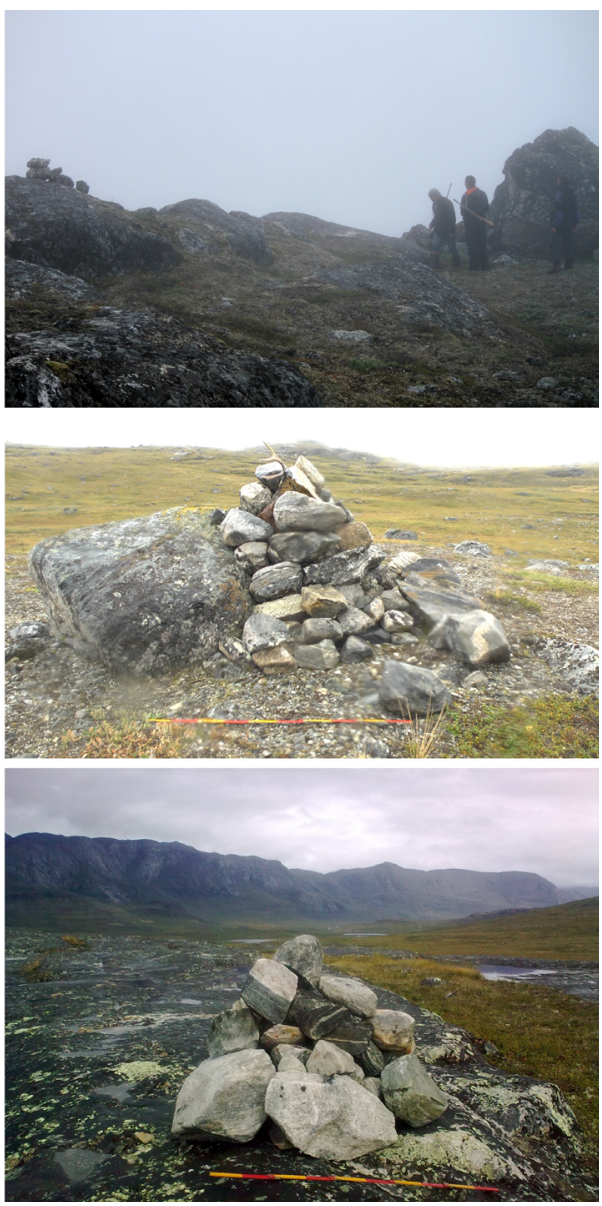

que suponía que gente de Nuuk y que él no las empleaba para guiarse ya que conocía perfectamente los alrededores de Kapisillit. También nos enseñó otra serie de estructuras que podían confundirse a distancia con las señales: las trampas para zorro -también amontonamientos de piedra, pero dotados de una galería en su parte inferior y una trampilla que encerraba al animal cuando éste disparaba el resorte al entrar-. Durante los días que pasamos cazando el caribú con Jakob y otros cazadores en Kapisillit, vimos inuksuit consistentes en amontonamientos cónicos de piedras, tanto de varias docenas de ellas como configurados sólo por unas pocas rocas. Ninguno superaba el metro de altura. El único amontonamiento peculiar detectado constaba de cientos de

Figura 4: Arriba: Inuksuk fotografiado durante la jornada de caza junto a Hans y Josef Josefsen en los alrededores de Kapisillit (foto S. D. DomínguezSolera). Medio: Inuksuk documentado durante la jornada de caza con Jakob Josefsen en los alrededores de Kapisillit (foto A. Pacios). Abajo: Inuksuk en el extremo sureste de Kapisillit, visible desde el valle que lleva al pueblo (foto S. D. Domínguez-Solera). 


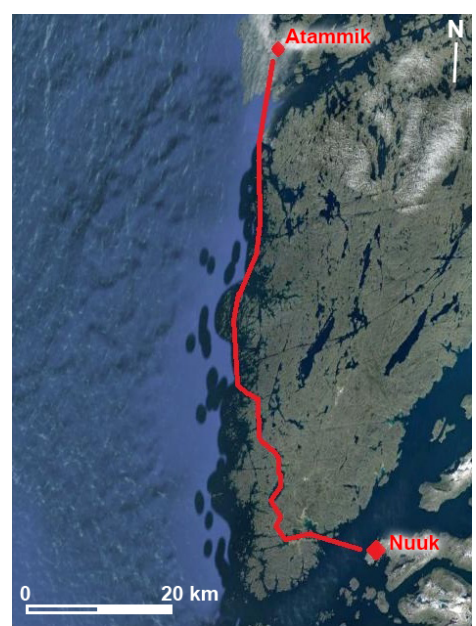

Figura 5: Ruta marítima de Nuuk a Atammik. (Sobre imagen de satélite de Google Maps).

Figura 6: Inuksuit en la costa entre Nuuk y Atammik. (Fotos: S. D. Domínguez-Solera).

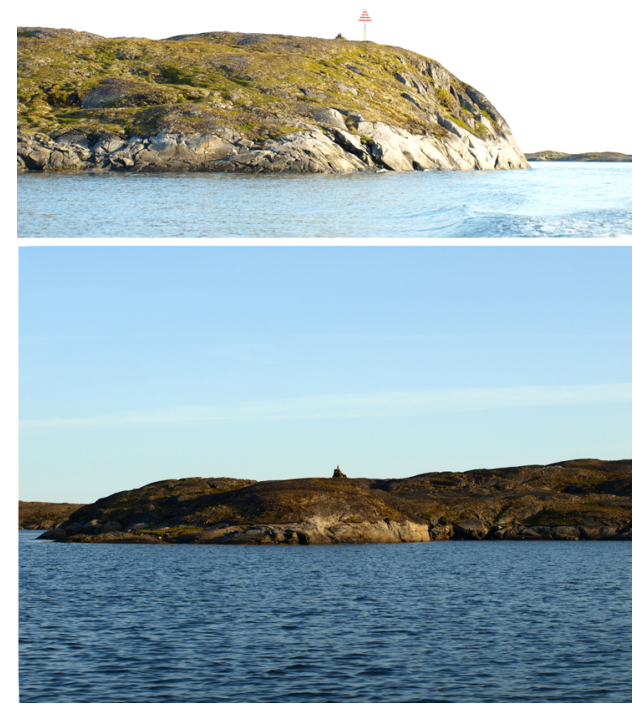

piezas pequeñas, estaba asociado a una gran roca y tenía en la parte alta una cuerna de caribú.

Hay que destacar también los inuksuit que se encontraban en el mismo extremo sureste del pueblo, visibles desde el fondo del valle antes siquiera de que lo fueran los tejados de las primeras casas. La razón de estos últimos parece obvia. Sin embargo, ningún vecino de Kapisillit pudo informarnos sobre el significado exacto de las estructuras que nos encontrábamos más allá de decirnos genéricamente que eran señales para guiarse. Tampoco obtuvimos más datos al respecto en Nuuk.

Desde Nuuk, contratamos un viaje en lancha motora hacia Atammik (Figura 5). Jon Korgh, gerente de ascendencia danesa de una oficina de turismo en la capital y afincado en Groenlandia desde niño, fue quien nos llevó personalmente. En el camino, por la costa y la parte más exterior de los fiordos encontramos decenas de inuksuit (Figura 6), además de algunas trampas para zorro. Aunque habíamos decidido ya empezar a documentarlos sistemáticamente para confeccionar mapas de dispersión, las condiciones del viaje -velocidad de la lancha, imposibilidad de parar y/o acercarnos a cada uno de los amontonamientos, etc.- no permitieron tal tarea. Sin embargo, al preguntar a Jon sobre los inuksuit que veíamos, éste nos confirmó que eran señales para la navegación. También nos explicó que en tierra servían para muchas otras cosas: recordar rutas, dejar mensajes a otras personas, que se les podían colocar cuernas encima, que servían para indicar rastros y, en definitiva, para la orientación en general.

Según Jon, las antiguas señales en el mar habían sido sustituidas por otras nuevas de código internacional (el cuadrado si ha de dejarse por el lado del mar, el triángulo 


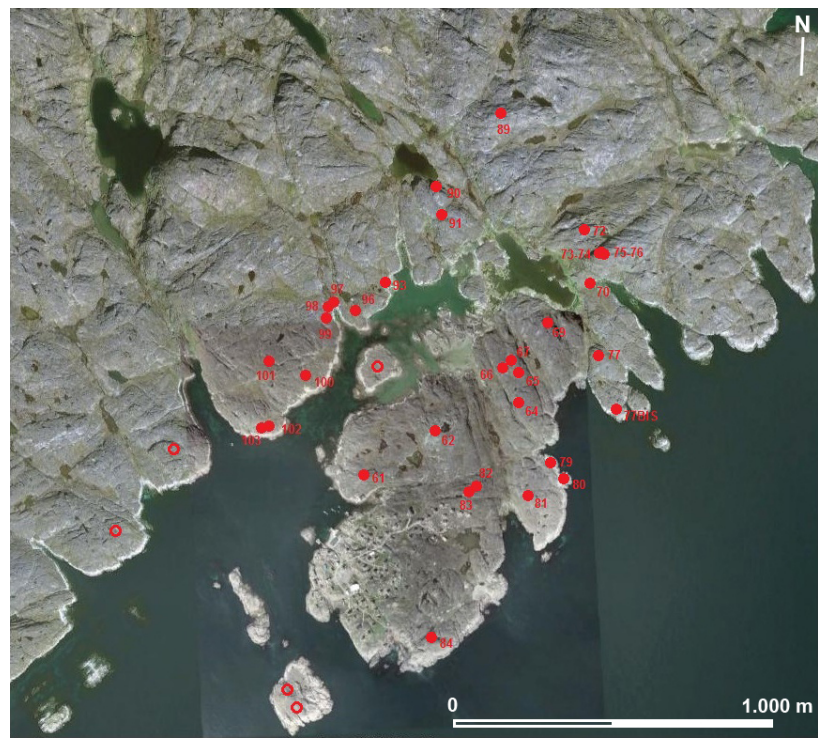

Figura 7: Plano de distribución de los Inuksuit de los alrededores de Atammik. (Sobre imagen de satélite de Google Maps).

si ha de tomarse por el lado de la tierra) hace 10 o 15 años. Las señales nuevas están indicadas en los mapas topográficos y en las cartas de navegación recientes. En el trayecto fue frecuente ver las antiguas señales, que ya no se mantienen pero sobreviven, junto a las nuevas de aluminio. Es bastante más que una anécdota el hecho de que, a mitad del viaje, se estropease el GPS y Jon tuviera que guiar la barca hacia Atammik empleando precisamente esas señales. Comprobamos así que tanto las marcas nuevas como las antiguas servían para orientar la navegación y llegar al destino de forma indistinta.

Todos los inuksuit que pudimos detectar -alrededor de 40, aunque es imposible precisar más el número al no poder verificar si eran tales, trampas para zorro, otras estructuras en piedra o casos naturales- tenían la misma morfología: amontonamientos de piedras de alrededor de un metro de altura, constituidos por una docena de piezas.

Durante las dos semanas que estuvimos en Atammik, además de ver más inuksuit durante las expediciones de caza y pesca en los alrededores, pudimos contrastar la información que nos había dado Jon Korgh durante el viaje desde Nuuk. También pudimos prospectar los alrededores del pueblo sistemáticamente para documentar mediante fotografías y coordenadas GPS la totalidad de estructuras conservadas en un área de 2 por 4 kilómetros aproximadamente (Figuras 7 y 8).

El tipo observado más numeroso era el de montones de una docena de piedras. Sólo encontramos un amontonamiento de piezas pequeñas de más de metro y medio y de más de un centenar de piezas (número 62 en el plano). También abundan los amontonamientos en los que una piedra alargada se coloca verticalmente sobre otras. Son también comunes los inuksuit que constan de un tronco de deriva -arrastrado hasta las costas groenlandesas desde áreas boscosas americanas- sujetado verticalmente con ayuda de piedras. Es destacable un inuksuk en forma de ventana (número 77). Por último es también necesario indicar que algunos inuksuit están agrupados a pocos metros unos de otros (103 y 103, 73 a 76 o 77 ). 

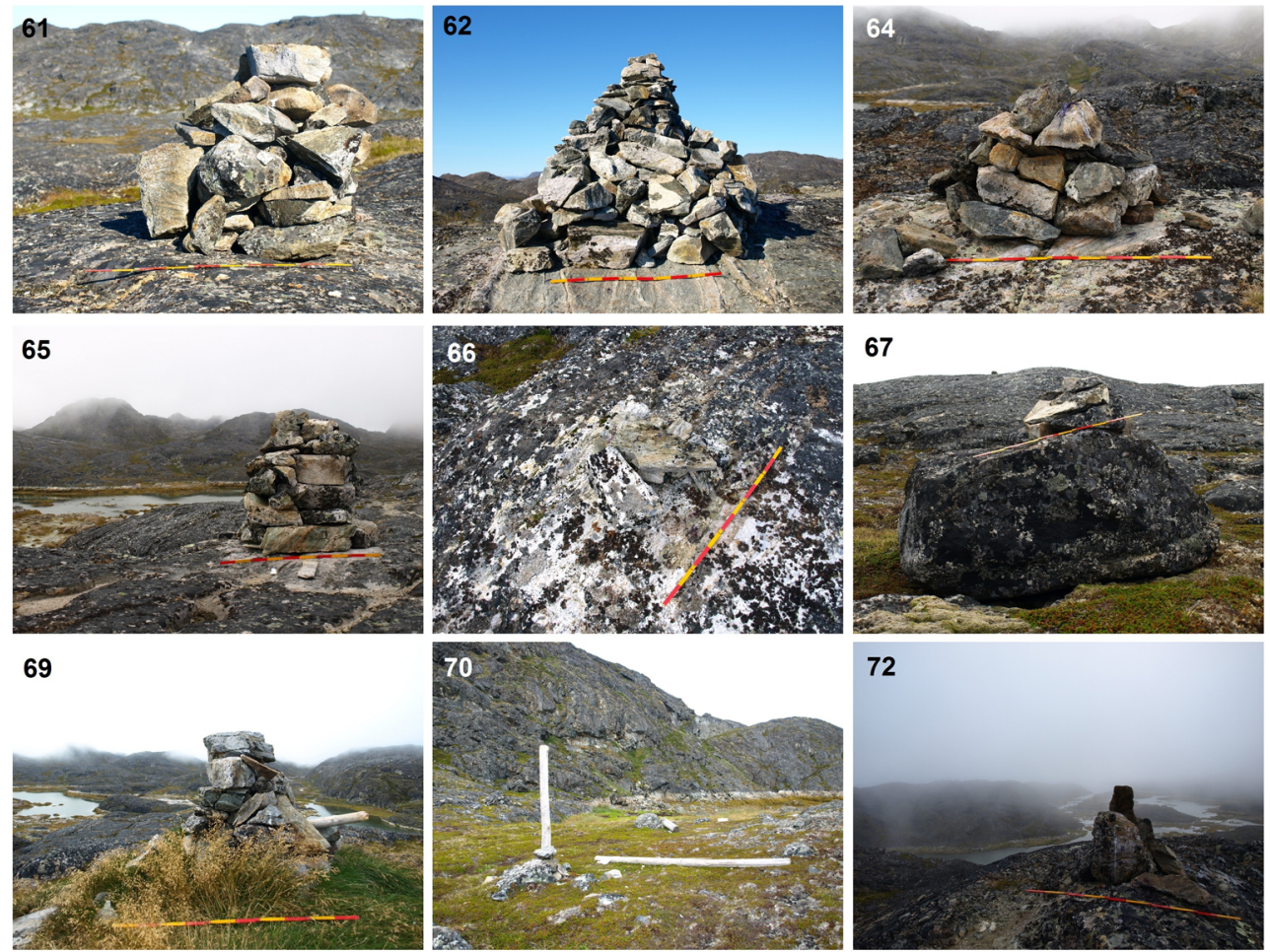

73

74

75
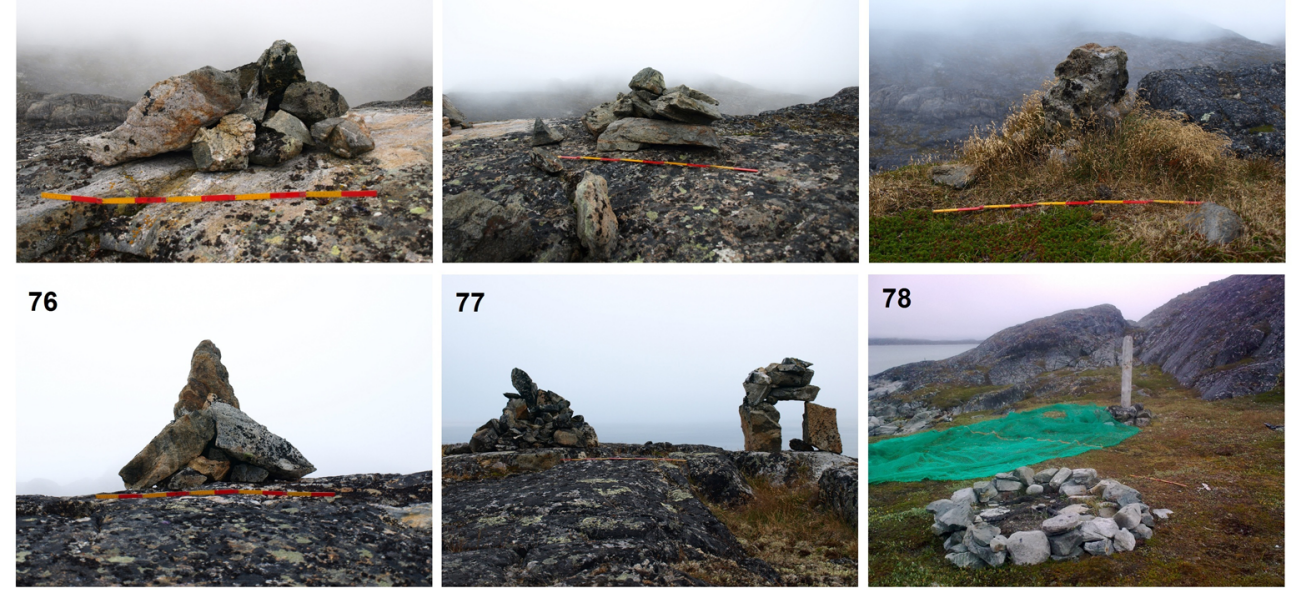

Figura 8: Inuksuit de los alrededores de Atammik. (Fotos: S. D. Domínguez-Solera). 

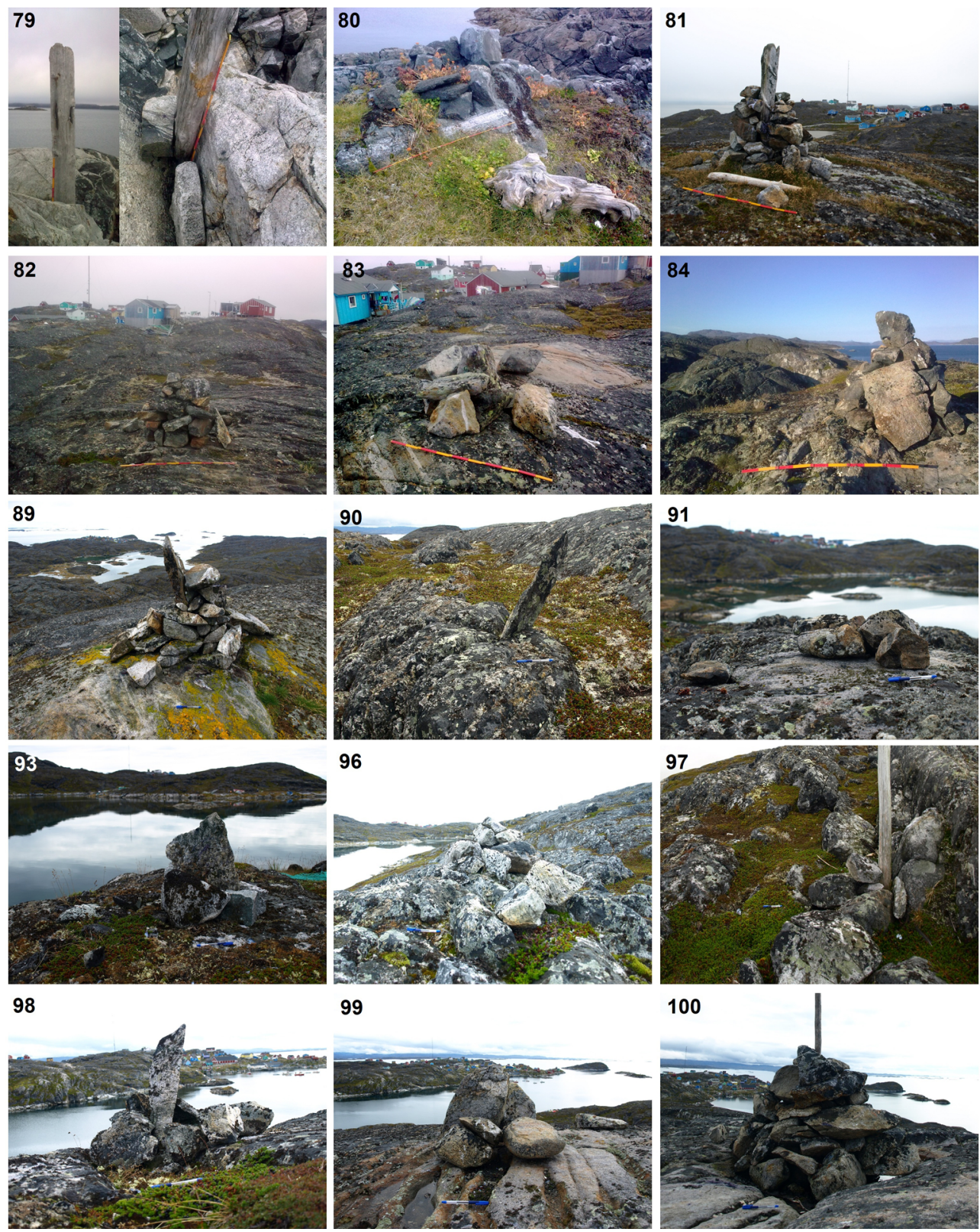

Figura 8: (contiuación). 



Figura 8: (contiuación).

Durante las prospecciones en los alrededores de Atammik pudimos también estudiar varias trampas para zorro, hogares y tumbas arqueológicas precristianas, estructuras en piedra cuyas fotos (Figura 9) enseñamos a los habitantes del pueblo para contrastar opiniones. Concretamente, Jørgen Olsen y su esposa Beathe, los maestros de la escuela de Atammik, nos ayudaron a identificar e interpretar las tumbas.

Tras enseñarles las fotos tomadas durante las prospecciones, Jørgen Olsen nos indicó que, al igual que en Canadá, las señales se conocen allí también como inuksuit. Destacó que se trataba de un símbolo identitario para los inuit en general, explicando que se hacían antiguamente y también en la actualidad aunque en menor cantidad. Su testimonio coincide con los que habíamos recabado antes en el sentido de que los inuksuit sirven para indicar rutas terrestres y marinas, la cercanía de gente o mensajes varios. Elias Josephsen, estudiante de peluquería de 24 años, también nos indicaría después todo esto. Hans ¿??, pescador de más de 57 años, a quien señalamos varios inuksuit mientras navegábamos por los fiordos, nos dijo que servían a la «old people» para navegar, mientras hacía el gesto de remar. Pero ninguno de los tres sabía qué significaban los inuksuit más concretos, indicándonos que eso lo habría sabido o lo podría saber solamente quien los hiciera.

Tampoco es anecdótico decir que, al volver de una prospección al norte de Atammik y al formarse niebla espesa, pudimos comprobar cómo los inuksuit eran siluetas visibles desde kilómetros en lo alto de las montañas (Figura 10) y, desde el norte, se podía así continuar el camino para llegar a Atammik. Se comprobó así en la práctica su ayuda en los desplazamientos terrestres, de la misma manera que los situados en la costa y en los fiordos, como ya dijimos, son ayudas para la navegación. Algunos inuksuit se encuentran inmediatos a trampas para zorros y a zonas transitables cuando baja la marea... Pero no podemos indicar la función de todas las señales que hemos mapeado y documentado en los alrededores de Atammik, dado que ni los habitantes de Atammik pudieron ser capaces de describirlas, lo que constituye un hecho muy elocuente sobre la naturaleza y percepción actuales de estas construcciones omnipresentes en el Paisaje. 

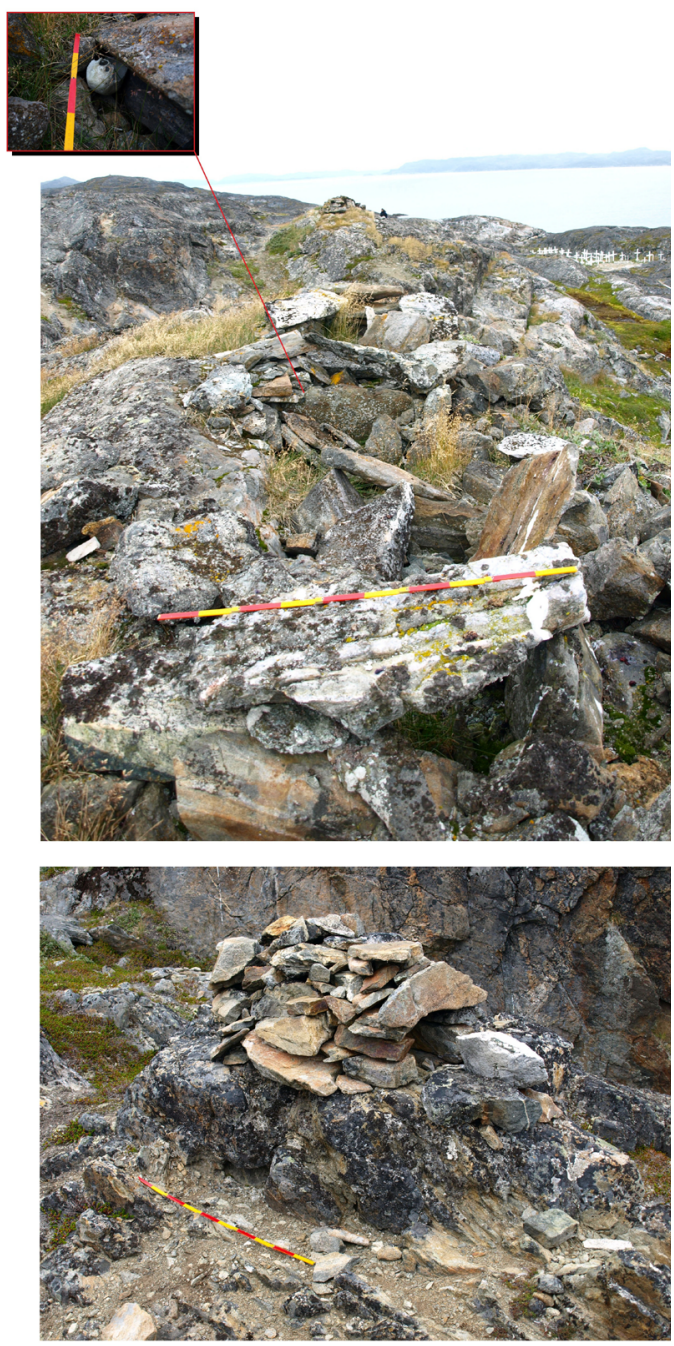

Figura 9: Arriba: Tumba antigua junto al cementerio actual de Atammik. Abajo: Una de las múltiples trampas para zorro de los alrededores de Atammik. (Fotos: S. D. Domínguez-Solera).

Lo que sí podemos concluir es que el conjunto de inuksuit de los alrededores de Atammik, como otros grupos en las inmediaciones de cualquier otro pueblo o ciudad, ha de entenderse como un palimpsesto de conjuntos y señalizadores individuales superpuestos, de varias épocas y con diversas funciones.

\section{Conclusiones}

Los inuksuit son la huella material de la relación ancestral de los inuit con el espacio. La mente humana ordena la realidad mediante dos parámetros, tiempo y espacio, y cada cultura construye su realidad según se entiendan éstos (Elias 1992; Hernando 2002: 51-52). En función del grado de complejidad socioeconómica que presenta un 
Figura 10: Inuksuit del norte de Atammik con niebla. (Fotos S. D. Domínguez-Solera).
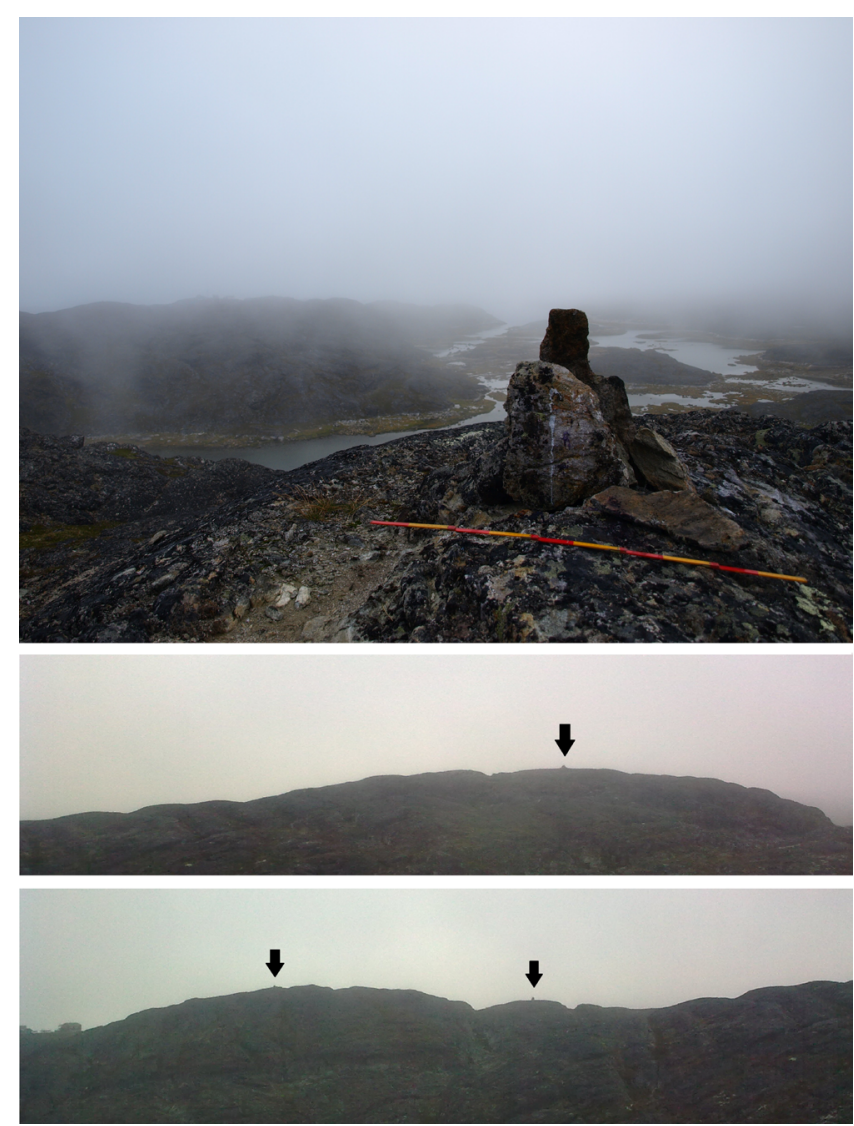

grupo humano, éste entenderá la realidad en la que vive de forma diferente (Hernando 2006: 28). Las sociedades tradicionales, distintas de la cultura capitalista actual, le daban y dan más importancia a la concepción del espacio que a la del tiempo. Como disciplina dedicada al estudio de las culturas pretéritas, la Arqueología ha de dar más peso al concepto tiempo que al concepto espacio (Criado 1993). Los estudios antropológicos, etnográficos y etnoarqueológicos han de basarse también en tal principio. En el marco de todos estos conceptos la Arqueología del Paisaje resulta útil, pues analiza el registro material para intentar entender la forma particular en que las comunidades del pasado tenían de percibir y entender el espacio, de relacionarse con él, explotarlo y modificarlo; de construirlo.

En principio, las comunidades cazadoras-recolectoras evitan y minimizan su incidencia sobre la naturaleza (Descola 2004), por lo que serán más «invisibles» en el registro arqueológico. Sin embargo los inuksuit son construcciones humanas visibles $\mathrm{y}$ tendentes a crear un paisaje domesticado, representando una actitud activa a la hora de relacionarse con el espacio (Lévi-Strauss 1964 y Criado 1993), a humanizarlo, siendo notable su visibilidad y su gran número. 
Para resolver la aparente incongruencia anterior es necesario entender que la forma de vida inuit resulta «atípica» si se compara con la de comunidades cazadoras recolectoras más meridionales, como fueron y en cierto modo lo siguen siendo los san del sur de África, los hadza de Tanzania, los aborígenes australianos, algunas tribus amazónicas no productoras tales como los nukak de Colombia o cualquiera de los grupos humanos del Paleolítico Europeo. Tales grupos representarían, por ejemplo y en lo referente a la movilidad, unas estrategias de vida nómadas. Por el contrario, las comunidades tradicionales de Inuit del oeste de Groenlandia, obligadas por las extremas condiciones climáticas del Ártico, no eran nómadas en sentido estricto, puesto que en invierno habitaban poblados de casas de piedra, mientras que en los meses más benignos del verano sí migraban y construían campamentos de tiendas en busca de recursos. Con tales recursos obtenidos en las migraciones del verano se podían pasar los meses de más frío y oscuridad. Es posible este sedentarismo estacional, dadas la mayor disponibilidad de recursos en la temporada veraniega, la posibilidad de acopiar reservas entonces y la especialización desarrollada por los habitantes del ártico en la depredación. Su forma de entender y relacionarse con el espacio, de construir el Paisaje en el pasado, hubo de ser también distinta a la de los cazadores-recolectores puramente nómadas.

Aunque la práctica de construir y emplear los inuksuit persiste en la actualidad, la cultura inuit poscolonial -cristianismo, escritura, capitalismo y globalización- no es por supuesto la misma que la tradicional milenaria, lo que hace imprescindible no intentar ver en el presente las claves directas para interpretar el pasado (González 2006). Estimado esto como filtro para la investigación, el inuksuk, como muchos otros elementos que aún hoy son símbolo de las naciones inuit, es inequívocamente una herencia de la forma de vida tradicional, estando comprobado su empleo continuado y sin interrupción desde hace milenios. Es un «fenómeno de larga duración» y su utilidad actual ha de guardar cierta relación con su significado y usos pretéritos.

Según la profesora Almudena Hernando (2002), las sociedades, arqueológicas y actuales, de cultura basada en la oralidad percibían, perciben, representaban y representan el espacio de forma «metonímica», mediante referencias mentales a hitos reales: referencias a lugares conocidos vivencialmente si se quiere. Por el contrario, las sociedades modernas lo hacen de forma radicalmente distinta $->$ metafórica $\rangle-$ debido a la capacidad de abstracción que concede el progresivo desarrollo de la individualidad (Hernando 2002); esta es la última razón de ser de los mapas.

Aunque ya se ha advertido la diferencia que significan con la forma de construcción del Paisaje de otras comunidades de cazadores-recolectores, los inuksuit son elementos totalmente coherentes con la racionalidad espacial de cualquier sociedad oral premoderna, no suponen una forma radicalmente diferente de entender el espacio a la de otras comunidades cazadoras-recolectoras y cumplen la misma función que valles, árboles, montañas o ríos tenían o tienen para pueblos de otras latitudes.

Es por lo tanto evidente el valor que tuvieron y aún tienen los inuksuit como marcadores espaciales y como instrumentos de orientación y también como mensajes en piedra o «semaliths» (Hallendy 1992). Scott Heyes indica (2002: 135) que los inuit del pasado sólo navegaban o viajaban por tierra guiándose mediante los inuksuit: también se conocen sus técnicas para emplear el sol, la luna, las estrellas, la aurora 
boreal, el viento, etc. Heyes habla de «mapas cognitivos», citando a Tuan (1979) y a Lynch (1960), para explicarlos como una librería de imágenes acumuladas y eventos derivados de viajes repetitivos, derivada de la experiencia y la interacción con el Mundo. Los inuksuit y todas esas técnicas son formas de entender el espacio y moverse por él, totalmente distintas a las que permiten y suponen mapas, el GPS o las señales de código internacional actuales. Por supuesto, los inuit hoy emplean mapas, pero aún sobrevive el inuksuk entre sus usos culturales como herencia de su forma de vida tradicional.

Como técnica de representación gráfica de la realidad, un mapa -entre otras cosassirve para explicar un espacio determinado a personas que no tienen por qué haber estado nunca en él, para indicarles distancias o rutas a seguir hacia su objetivo. Es indispensable destacar que los inuksuit, sin ser mapas pero gestados dentro de unos patrones de raciocinio radicalmente distintos, cumplían y cumplen eficientemente la misma función que aquellos. Aquí radica su valor dentro de las investigaciones sobre construcción y percepción espacial.

Para terminar: José Andrés Alonso de la Fuente habla de otros casos en el mundo, de construcciones parecidas, pero no iguales, no habiendo casos que cumplan funciones similares para la caza y la orientación; sólo ciertos torreones del paisaje chino sirven para guiar al ser humano en sus viajes (Alonso 2006: 212-213). Los inuksuit son hoy un caso único en el Mundo. ¿Lo son realmente? ¿Lo han sido siempre? ¿Habrán existido soluciones similares en el pasado?

\section{Referencias bibliográficas}

Alonso de la Fuente, José Andrés

2006 «Los inuksuit: otra forma de ver el mundo». Revista Española de Antropología Americana 36: 203-213.

BINFORD, Lewis R.

1988 En busca del pasado. Barcelona: Crítica.

Criado Boado, Felipe

1993 «Límites y posibilidades de la Arqueología del Paisaje». SPAL 2: 9-55.

Descola, Philippe

2004 «Las cosmologías indígenas de la Amazonía», en Tierra Adentro. Territorio indígena y percepción del entorno, Alexandre Surrallés y Pedro García Hierro, eds., pp. 25-35. Copenhague: IWGIA.

ELIAS, Norbert

1992 Time, an Essay. Oxford: Basil Blackwell.

GonZÁlez Ruibal, Alfredo

2006 «El giro poscolonial: hacia una etnoarqueología crítica», en Etnoarqueología de la prehistoria: más allá de la analogía, pp. 41-60. Treballs d'Etnoarqueologia, 6. Barcelona: Consejo Superior de Investigaciones Científicas.

GrabURn, Nelson

2004 «Inuksuk: Icon of the Inuit of Nunavut». Étudies/Inuit/Studies 28 (1): 69-82. 
Grønnow, Bjarne, Morten MeldgaARd y Jørn Berglund Nielsen

1983 Aasivissuit, the Great Summer Camp: Archaeological, Ethnographical and ZooArchaeological Studies of a Caribou-Hunting Site in West Greenland. Copenhage: Commission for Scientific Research in Greenland.

HALLENDY, Norman

1992 «Inuksuit: Semalithic Figures Constructed in the Canadian Arctic». Ponencia presentada en la $25^{\text {th }}$ Annual Meeting of the Canadian Archaeological Association, Ontario.

HALLENDY, Norman

1997 «The Silent Mesengers». Equinox 85: 36-46.

HeYEs, Scott

2002 «Protecting the authenticity and integrity of inuksuit within the arctic milieu». Étudies/Inuit/Studies 26 (2): 133-156.

HERNANDO, Almudena

2002 Arqueología de la identidad. Madrid: Akal.

2006 «Etnoarqueología y globalización. Propuesta de una etnoarqueología estructuralista», en Etnoarqueología de la prehistoria: más allá de la analogía, pp. 25-32. Treballs d'Etnoarqueologia, 6. Barcelona: Consejo Superior de Investigaciones Científicas.

LÉvi-Strauss, Claude

1964 El pensamiento salvaje. México: Fondo de Cultura Económica.

LYNCH, Kevin

1960 The Image of the City. Cambridge: MIT Press.

STEFÁnSSON, Vilhjarmur

1922 The Friendly Arctic: The Story of Five Years in Polar Regions. Nueva York: The Macmillan Company.

TuAn, Yi-Fu

1979 Space and Place: The Perspective of Experience. Minneapolis: University of Minnesota Press. 